\title{
Split-Thickness Skin Grafts
}

\author{
Tamer Seyhan \\ Adana Numune Educ. E Train. Hospital \\ Turkey
}

\section{Introduction}

The use of split-thickness skin grafts (STSG) is the most common performed procedures to close defects unable to be closed with the simple approximation of the wound edges. The healing of a STSG donor site involves re-epithelialization from the epithelial appendages that are embedded in the dermis and subcutaneous fat.

STSGs are easy to harvest and are taken directly with a knife or with an instrument such as a dermatome. STSGs may be expanded in size using a meshing device or surgical knife.

The following topics are discussed in this chapter:

- Components of skin

- Classification of split thickness skin grafts

- Process of graft take and healing

- Indications and contraindications of split thickness skin grafts

- Preoperative considerations

- Split thickness skin graft donor sites and harvesting the graft

- Postoperative care of split thickness skin grafts and management of donor site

- Complications of split thickness skin grafts

- Preservation of split thickness skin grafts.

\section{Components of skin}

Skin consists of two layers derived from two different embryonic layers. The thinner, outermost layer is the "epidermis", which is derived from ectoderm; the thicker, innermost layer is the "dermis", which is derived from mesoderm. The epidermis accounts for approximately $5 \%$ of the skin thickness and the dermis comprises the remaining $95 \%$ (Vitness, 1977). The dermis contains connective tissue and skin appendages such as sebaceous glands, hair follicles and sweat glands. Although sebaceous glands are seated in the dermis, the hair follicles and sweat glands extend into subcutaneous fat.

The average thickness of human skin varies between 2 and $3 \mathrm{~mm}$. Skin is thickest in the sacrum, palms, and soles of the feet and is thinnest in the eyelids and in the postauricular area. The epidermis of the face is relatively constant in thickness and measures approximately 150 microns; however, dermal thickness varies considerably. The dermis can be as thin as $200-250 \mu \mathrm{m}$ in the eyelid and periorbital area, $900-1000 \mu \mathrm{m}$ in the lip and forehead regions and as thick as $3 \mathrm{~mm}$ on the back skin (Gonzalez-Ulloa et al., 1954).

There are five distinct cellular layers of the epidermis. These layers include (from deep to superficial) the stratum basale (stratum germinativum), stratum spinosum (prickle cell 
layer), stratum granulosum, stratum lucidum, and stratum corneum. The Malpighian layer of the skin is a term that is generally defined as both the stratum basale and stratum spinosum as a unit. The cells of the epidermis arise from the stratum basale and are called keratinocytes. Keratinocytes gradually migrate superficially and fill with keratin and lipids and undergo desquamation throughout life. It has been determined that the renewal time of the Malpighian layers is about 19 days (Stal et al., 1987). Thus, each epidermal cell spends an average of 10 days in its migration to the surface. In addition to keratinocytes, melanocytes, Langerhans, and Merkel cells are also present in the epidermal layer of the skin. Melanocytes, found in the stratum basale, produce melanin, which is distributed to the epidermal cells and imparts characteristic pigmentation to the skin. Melanin also shields the skin from the deleterious effects of ultraviolet radiation by absorbing UV light and trapping photochemically activated free radicals. The Langerhans cells play a vital role in the immune response by identifying and processing the antigens for other local immunocompetent cells. The Merkel cells are found in the stratum basale clustered around hair follicles and are especially concentrated in the palms and soles. These cells also act as slowly adapting pressure mechanoreceptors.

The dermis consists of two layers: a thin outer papillary layer and a thick inner reticular layer. The papillary layer consists of randomly arranged collagen fibers, fine elastic fibers, and abundant ground substance. The ground substance consists of extracellular fluid and mucopolysaccharides, primarily hyaluronic acid, chondroitin sulfates, and glycoproteins. The proportion of ground substance and the production and turnover of collagen decreases with age and is replaced with fibrous intercellular tissue. The reticular layer is formed by dense, coarser, branching, collagenous fibers arranged in layers, mostly parallel to the surface. Fibroblasts make up the majority of cells in the dermis, along with interspersed mast cells and tissue macrophages. The structural strength of the dermal layer is provided by collagen. Collagen fibers are synthesized by dermal fibroblasts. The majority of collagen in the dermis is Type I collagen and constitutes up to $80 \%$ of the collagen in skin. Type III collagen constitutes about 15\%, while Type V and Type VI account for the remainder. The typical ratio of Type I collagen to Type III collagen is 4:1( Kusuma et al., 2010).

The dermo-epidermal junction of human skin appears as an irregularly, wavy line; the ridges or rete pegs project into the dermis. With aging, these rete pegs diminish and subsequently lead to a decrease in the surface area of the dermal-epidermal junction. Branches from cutaneous arteries form a small vessel plexus within the dermis. The lymphatic plexuses are found in the papillary dermis, directly below the dermal papillary ridges. The skin possesses a rich supply of sensory nerves, which are organized as deep dermal and superficial dermal plexus. These nerves convey sensation from the skin to the brain through specialized receptors for touch (Meissner's corpuscles), pressure (Pacinian corpuscles and Merkel cells), temperature and pain (free nerve endings) Additionally, a network of autonomic fibers provide the primary innervation of cutaneous blood vessels, pilomotor units in the hair follicles, and the sweat and sebaceous glands (Gaboriau \& Murakami, 2001).

Sweat glands, sebaceous glands and hair follicles are skin appendages. Sweat glands are found deep in the dermis and even in the subcutaneous tissue. The sweat glands are usually located deeper than the hair follicles; however, hair follicles reach in the subcutaneous fat of the bearded area of the male face. There are two types of sweat glands, apocrine and eccrine. The more numerous eccrine sweat glands are found over the general body surface of 
humans and open either at the sweat pores on the skin surface or above the opening of the sebaceous gland in the hair follicle walls. Apocrine sweat glands tend to be concentrated in the eyelids, axillae, periumblical area and genital area. The apocrine glands become more active at puberty secrete continuously. The secretions of apocrine glands produce a characteristic odor; however, the eccrine glands are odorless.

Sebaceous glands are derived from the pilosebaceous unit and are commonly associated with hair follicles. The sebaceous glands provide lubricant for the hair and skin and are larger and have more density in the skin of the forehead, nose, and cheeks.

Hair follicles are intradermal epithelial invaginations associated with sebaceous glands and smooth-muscle bundles called erector pili.

\section{Classification of split-thickness skin grafts}

Skin grafts are classified according to origin and thickness. Skin grafts are classified as autograft, allograft (homograft), xenograft (heterograft) and isograft (syngenic) according to the sources. An autograft is a graft transferred from a donor to recipient site in the same individual. An allograft (homograft) is a transplant between individuals of the same species. A xenograft (heterograft) is a graft transplanted between individuals of different species. An isograft (syngenic) is a graft transplanted between genetically matched genotypes, such as identical twins.

Split-thickness skin grafts (STSGs) are subdivided into thin, medium and thick STSGs.

- $\quad$ Split-thickness skin graft-thin (STSG-T; 0.008-0.012 in. or 0.2-0.3 mm)

- $\quad$ Split-thickness skin graft-medium (STSG-M; 0.012-0.018 in. or 0.3-0.45 mm)

- $\quad$ Split-thickness skin graft-thick (STSG-THK; 0.018-0.030 in. or 0.45-0.75 mm)

The STSG-T used by early surgeons such Ollier (1872) and Thiersch (1874) have been replaced by thicker split-thickness grafts (STSG-M, STSG-THK), which include all of the epidermis and a variable fraction of the dermis (Blair \& Brown, 1929). Currently, the most commonly used split-thickness graft thickness is between 0.012 and 0.018 inch ( 0.30 to 0.45 $\mathrm{mm}$ ) in thickness. The average STSG is cut at 0.015 inch and can be checked by inserting a No.15 blade, which approximates that thickness.

The mesh skin graft was first described by Tanner in 1964 as a method of expanding skin grafts (Tanner et al., 1964). Preparation of the meshed skin graft is performed with a skin graft mesher. The graft is placed on a template and is passed through the device. The most commonly used expansion ratio is 1:1.5, which increases the surface area by 50 percent. Mesh grafts are primarily useful in two situations: (1) when there is insufficient skin; or (2) when a very irregular surface must be covered with a graft where a sheet might not adhere well (Fig. 3c). Also, the drainage of fluid through the slit-like perforations produced by the meshing procedure prevents hematoma formation and permits the graft to be applied to an actively bleeding wound. The expanded graft must heal in between the expansion by epithelization; therefore, the underlying wound may contract significantly.

\section{Process of graft take and healing}

Grafts initially survive via diffusion, called plasmatic imbibition, and subsequently inosculation and revascularization occurs. Immediately after a skin graft is placed on the recipient bed, a fibrin network provides a scaffold for the necessary graft adherence. During 
the first 48 hours, the graft becomes engorged with plasmatic fluid by means of diffusion. A poorly vascularized bed requires a longer period of plasmatic imbibition before the graft is revascularized. The ingrowth of capillary buds from the recipient bed into the open vessels on the undersurface of the graft is called inosculation and occurs within 2 to 4 days. Revascularization is thought to be directed by angiogenic factors and can be restored within 5 to 7 days. Thin grafts of skin are revascularized more rapidly than thick grafts. Lymphatic circulation, which is established by the fifth day, may aid in decompressing the increased graft interstitial fluid. Within the first week the thickness of the epidermis can increase seven to eightfold. Dermal fibroblasts proliferate vigorously in healing skin grafts after an initial decrease of three days. By the seventh to eighth day there is a marked hyperplasia of fibroblasts as the graft begins to heal.

Almost all skin grafts are capable of sweating in response to stimulation of the nerves that ingrow from the recipient site. STSGs often have deficient function of sebaceous glands and therefore should be lubricated for three months. Most patients with skin grafts do not obtain completely normal sensation. The recovery of sensation in humans can begin as early as one to two months after surgery, and may be abnormal during the first year. Full-thickness skin grafts appear to achieve better sensation than split-thickness grafts, although the rate of return of innervation is faster in STSGs.

\section{Indications and contraindications of split-thickness skin grafts}

\subsection{Indications of split-thickness skin grafts}

- Immediate coverage of clean soft tissue defects and accelerated wound healing (Fig. 1a,b.)

- Immediate coverage of burn defects and reduced fluid loss from the wounds.

- Prevention of scar contracture and enhanced cosmesis in superficial wounds.
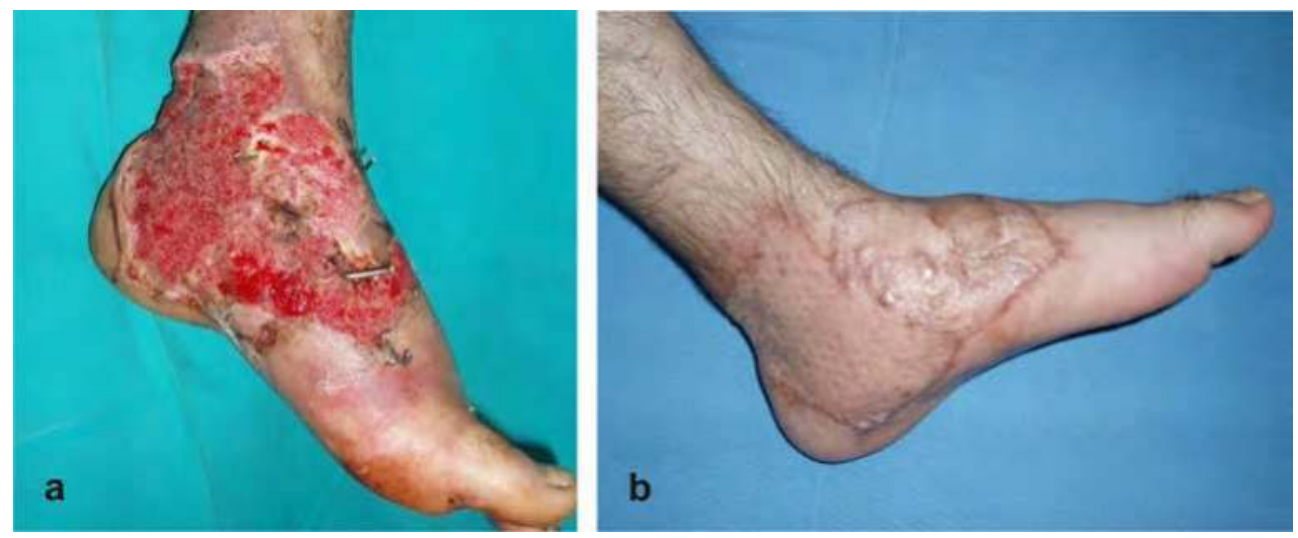

Fig. 1. (a) View of the traumatic clean soft tissue defect before split-thickness skin grafting.

(b) Post-operative view of the patient after split-thickness skin grafting.

\subsection{Contraindications of split-thickness skin grafts}

- Infected wounds have poorly vascularized and necrotic tissue. After management of the infection and necrotic tissues, skin grafting becomes suitable (Fig. 2a,b,c; Fig. 3 a,b,c,d). 


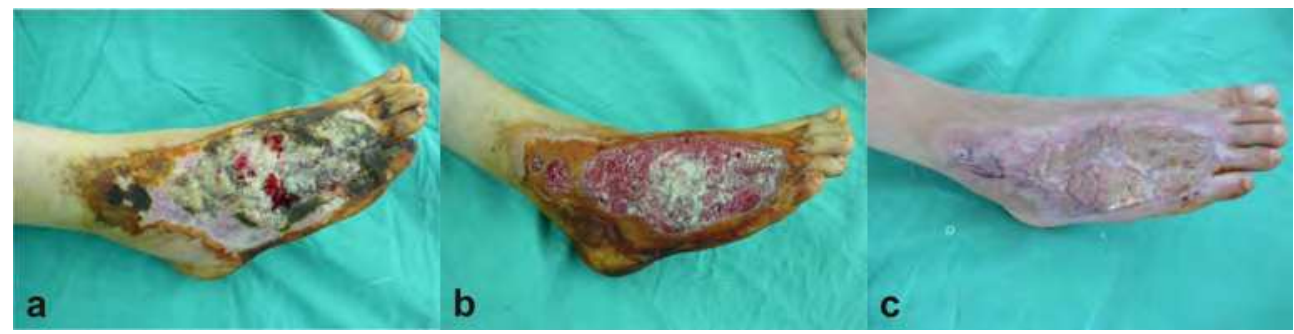

Fig. 2. (a). Preoperative view of infected, poorly vascularized wound with necrotic tissues. Fig. 2. (b). After management of the infection and necrotic tissues of the wounds.

Fig. 2. (c). Postoperative view of the defects after split-thickness skin grafting.
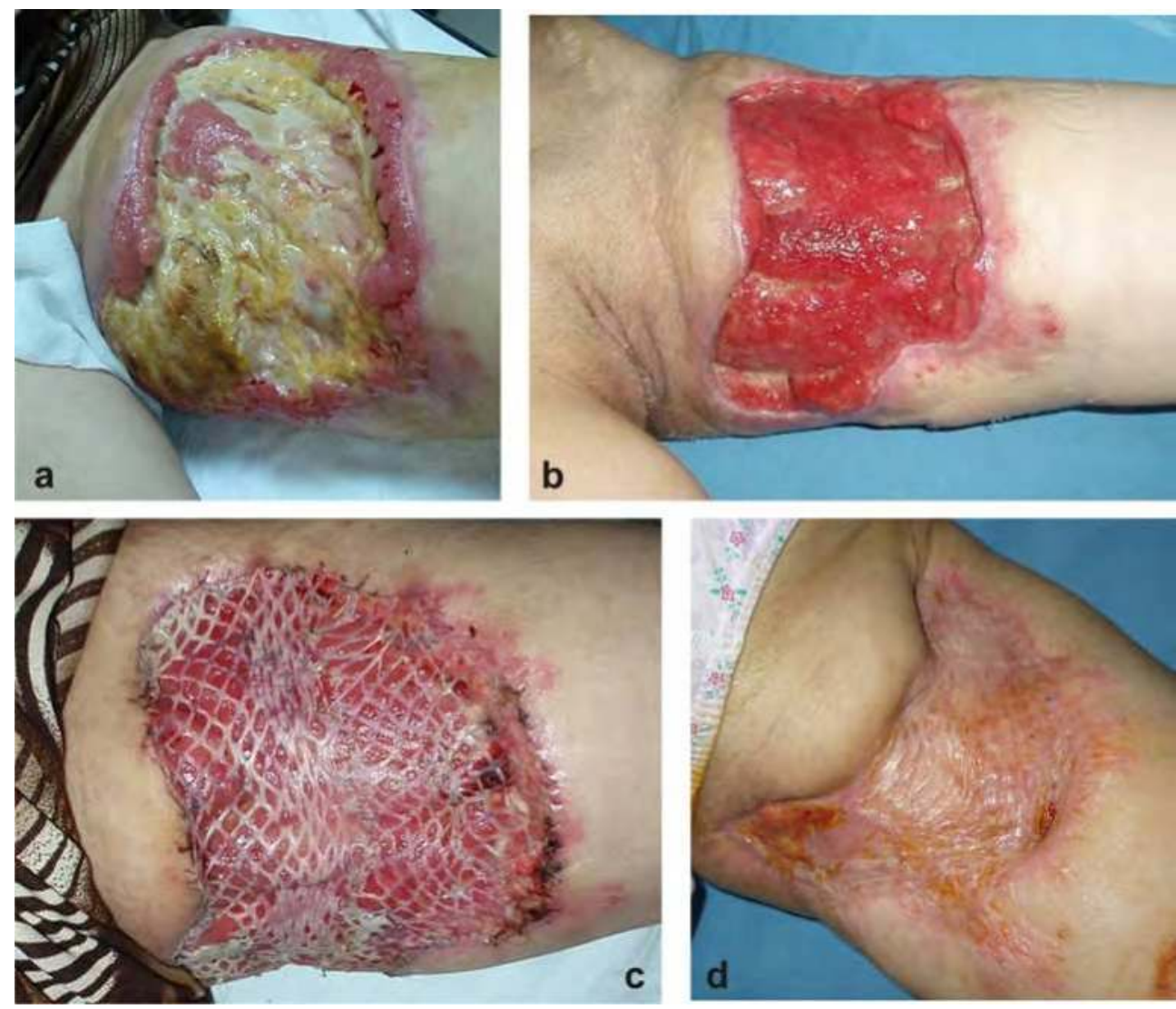

Fig. 3. (a). Preoperative view of infected, poorly vascularized wound with necrotic tissues. Fig. 3. (b). After management of the infection and necrotic tissues of the wounds.

Fig. 3. (c,d). Postoperative view of the defects after split-thickness skin grafting. 
- Exposed bone without periosteum, cartilage without perichondrium, tendon without paratenon or nerve structures (Fig. 4.).

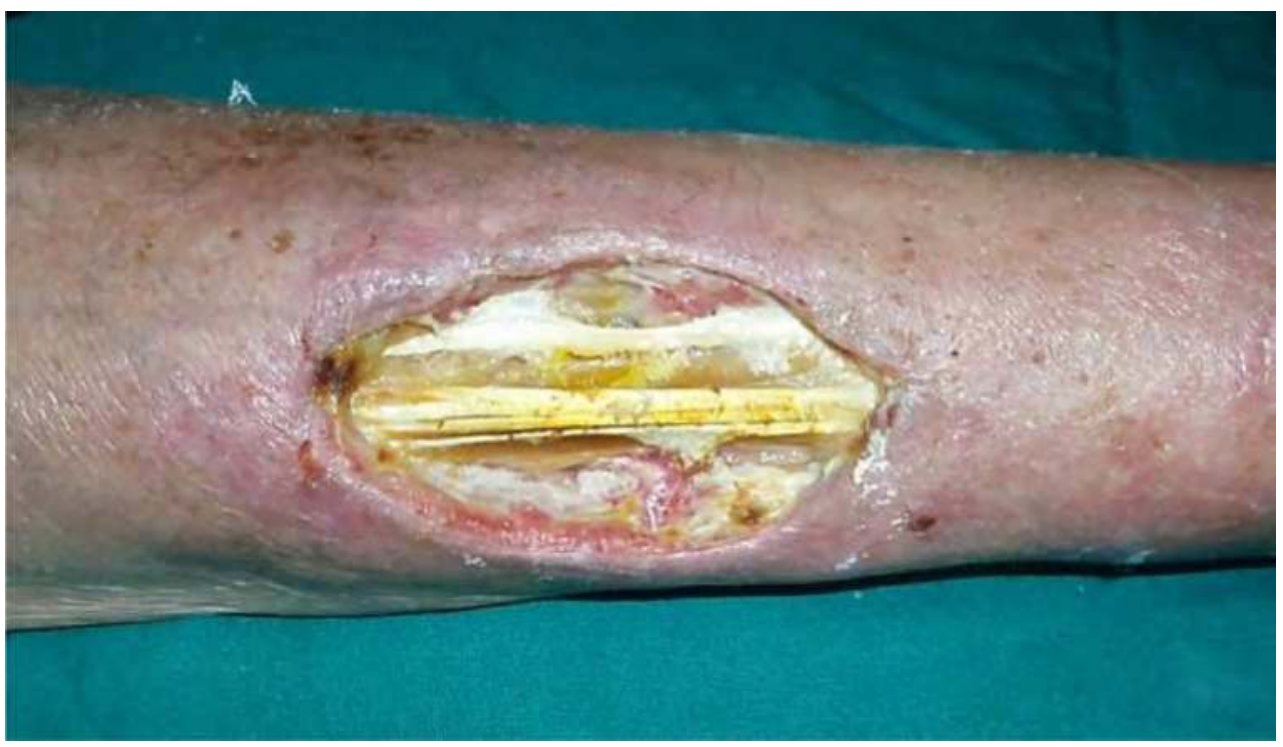

Fig. 4. View of the defect on the cruris, which is not suitable for grafting.

\section{Preoperative considerations}

Wounds considered for skin grafting must have a well vascularized and non-infected wound bed. A granulating wound with a healthy appearance usually denotes sufficient nutritional status and overall health of the patient (Fig. 2b, 3b). Hypertrophic granulation tissue needs to be either trimmed or flattened in order to enhance graft take and epithelial migration. Epithelial migration at the edges of the granulating surface may be a sign that the wound is ready for application of a skin graft. Serial debridements, culture-specific antibacterial therapy and frequent dressing changes continue to be the mainstay of preparing good recipient bed.

Pretreatment of a wound with vacuum-assisted closure (V.A.C. ${ }^{\circledR}$ KCI, USA, Inc., San Antonio, TX, USA) therapy is advisable to increase granulation tissue, tissue perfusion and decrease edema, bacterial colonization, wound exudate in chronic wounds (Fig.5 a,b,c) (Teot, 2004). VAC therapy consists of a controlled application of continuous or intermittent subatmospheric pressure to a sponge-like wound dressing to promote healing (Argenta \& Morykwas, 1997). Classic VAC therapy is not advisable when the wound is infected. An alternative method for infected wounds is the use of V.A.C. ( ${ }^{\circledR}$ Instill ${ }^{\mathrm{TM}}$, which has an additional instillation line for topical antiseptics and antibiotics and removal of topical solutions from the wound site (Bernstein \& Tam, 2005). Silver-impregnated sponges (V.A.C. GranuFoam Silver $\left.{ }^{\circledR}\right)$ provide continuous delivery of silver directly to the wound bed and may be preferred in infected wounds during VAC therapy. 

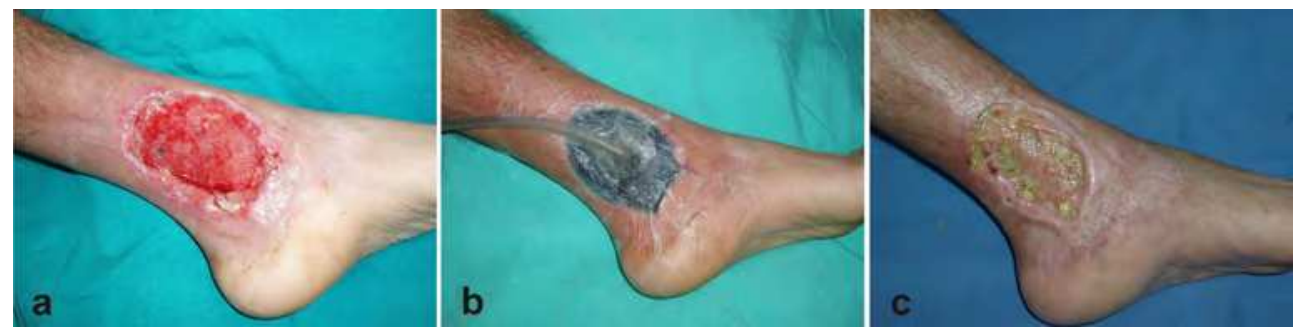

Fig. 5. (c) View of a venous ulcer on the left medial malleolus. (b) The use of VAC dressing for preparing the wound bed for grafting. (a) View of the freshly granulating venous ulcer defect after four VAC dressing changes.

\subsection{Split-thickness skin graft donor sites and harvesting the graft}

STSGs can be taken from any area of the body, including the scalp and extremities (Fowler \& Dempsey, 1998). When possible, STSGs should be taken from hidden areas such as the anterolateral thigh and lateral buttock. If STSGs are required for the face, skin harvested from "blush zones" such as the supraclavicular area and scalp is preferable. A thin graft (0.010 inch or less) leaves the hair follicles in the donor scalp and avoids hair growth in the recipient bed. Also, an important source of STSGs is avulsed skin in trauma or surgically removed skin.

Skin graft harvesting can be performed by various tools including knives and dermatomes (Table 1, Fig. 6 a,b,c,d).

Skin graft harvesting tools

1. Free-hand knives

2. Various types of dermatomes

- $\quad$ Drum (manually operated)

- $\quad$ Powered dermatomes (Electric or air);

- Battery operated Davol dermatome

- Humeca Battery operated dermatome

- Padgett dermatome

- Zimmer air dermatome

\section{Table 1. Skin graft harvesting tools}

Free-hand knives are manual dermatomes. The large Humby-type knives and smaller Goulian type knives are used for harvesting the STSG manually but provide grafts with irregular edges and grafts of variable thickness (Fig. 6a). Of the powered dermatomes, the Padgett dermatome is lighter and is easy to handle and comes in three widths: small-3 inches wide, medium- 4 inches wide, and giant-5 inches wide (Fig.6c). The thickness is determined by turning the setting dermatome knob to the appropriate thickness.

The dimensions of the graft are marked 15-20\% larger than the dimensions of the defect. The skin is lubricated with sterile Vaseline ointment to facilitate graft cutting. It is essential to keep the donor area surface flat, taut and stretched, for smooth, uniform thickness during graft cutting. An assistant applies counter-tension on the skin during advancing of the dermatome and graft harvest is performed in a proximal to distal direction. An surgical 
assistant can pick up the ends of the skin graft with forceps while the surgeon harvests the graft with the dermatome.

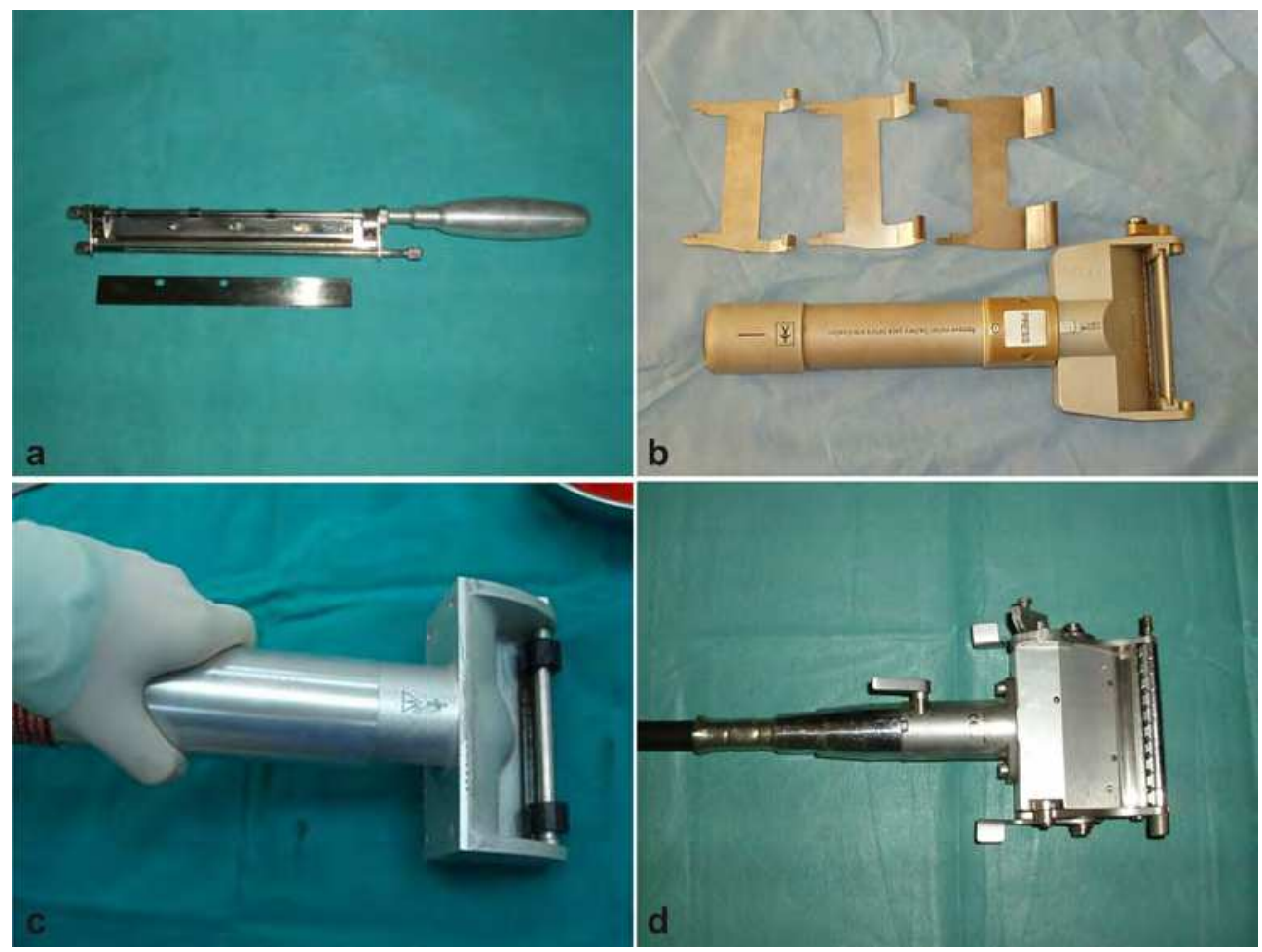

Fig. 6. The most popular tools for skin graft harvesting. (a) Watson's modification of Humby knife. (b) Humeca Battery operated dermatome. (c) Padgett Dermatome. (d) Zimmer air dermatome.

\subsection{Postoperative care of split-thickness skin grafts and management of donor site}

The graft is placed on the recipient bed, trimmed with scissors and fixed with sutures or metal staples. Serous fluid or blood beneath the graft can be a barrier to graft take and a source of infection that will result in graft loss. Multiple small "pie crust" incisions with a $\neq 11$ scalpel blade or fine scissors provide drainage of the fluid or blood beneath the graft. In most cases of skin grafting, the optimal dressing is a bolus or tie-over dressing to ensure contact and immobilization between the graft and the host bed. A circumferential compression dressing and a plaster can be used for immobilization in extremity skin grafts. A tie-over dressing is fashioned by placing sutures around the periphery of the graft and is tied over a piece of fine mesh, ointment impregnated gauze, covered with cotton sheeting or cotton balls. The tied sutures gently press the dressing down onto the skin graft, which in turn is pressed onto the wound bed. This maneuver immobilizes the graft on the wound and prevents hematoma collection. Before the tie-over dressing is applied, the surgeon should ensure that there are no blood clots underneath the graft. The tie-over dressing is left in 
place for three or four days. After removal of the dressing, small collections of seroma may be evacuated by cutting over the top of the graft and an ointment impregnated gauze dressing applied for another 2 or 3 days. When the skin graft is stable and adherent, antibiotic ointment or another mild lubricating agent is used for three months.

Negative pressure dressing (VAC $\AA$ therapy) can be used to facilitate skin graft adherence when grafting difficult wounds (e.g. radiated wounds, wounds with irregular or mobile recipient beds and in difficult anatomic locations (Schneider et al., 1998; Scherer et al., 2002) (Fig. 7a,b,c,d.). The VAC dressing is applied to the STSG at $125 \mathrm{mmHg}$ "continuous" mode suction after the STSG is covered with a single layer of non-adherent Chlorhexidine or Xeroform gauze.
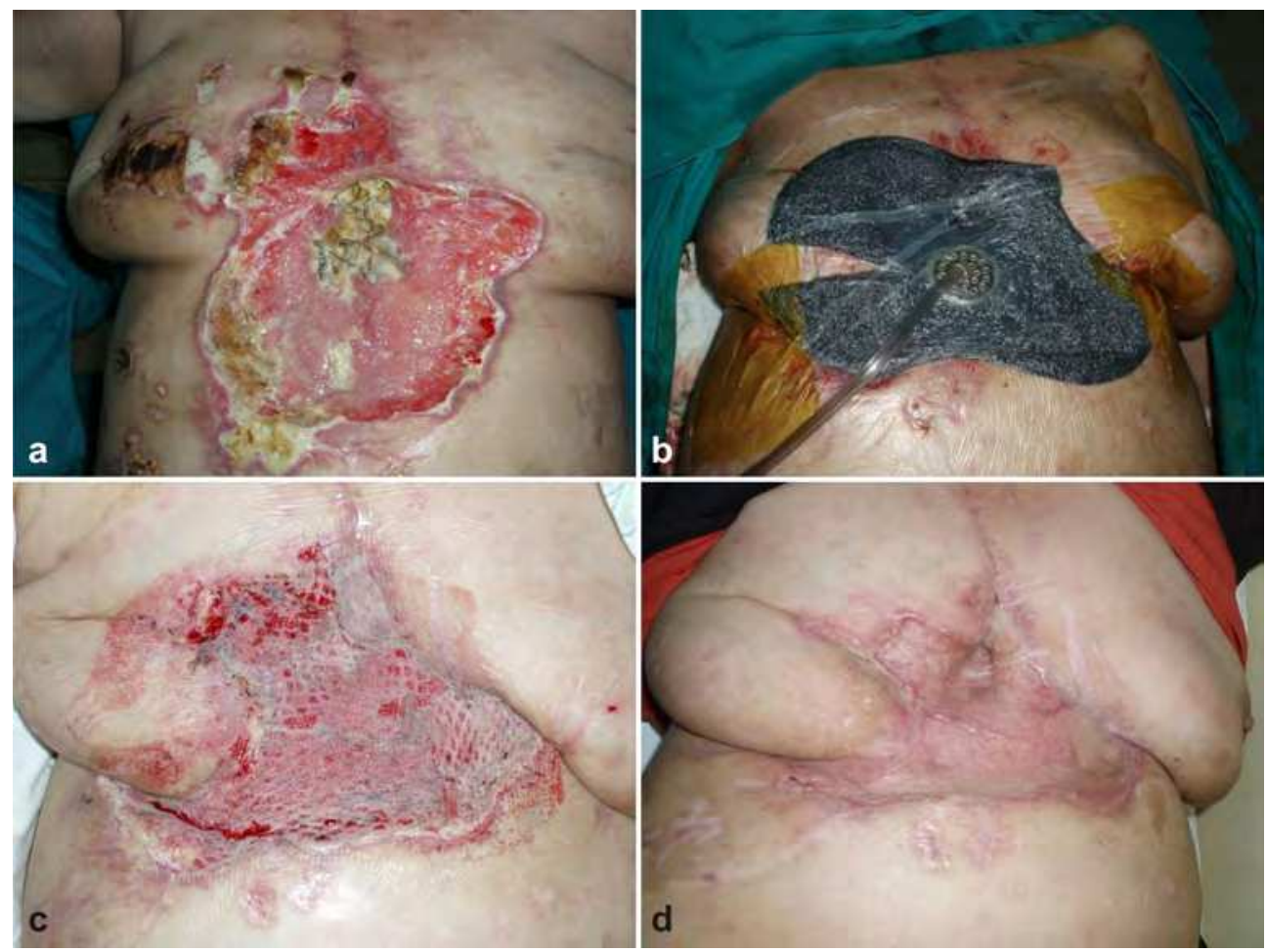

Fig. 7. (a) View of sternal wounds with irregular and mobile recipient bed. (b) Application of VAC dressing on STSG covered with a single layer of non-adherent Chlorhexidine gauze. (c) View of grafted defect after removal of VAC dressing on the fourth postoperative day. (d) Late postoperative view of the same patient.

\subsection{Donor site healing and maintenance}

The healing of the donor site occurs by epithelial migration from the epithelial remnants in the dermis such as hair follicles, sebaceous gland, and sweat glands. Epithelial migration also occurs at the wound margins. After harvesting a STSG, the donor site is treated with topical, epinephrine-soaked sponges to reduce bleeding and then a single layer of non- 
adherent Chlorhexidine or Xeroform gauze is applied to the donor site, followed by a layer of bulky gauze on top of this. The next day, the outer gauze is removed, leaving behind the Chlorhexidine or Xeroform gauze, which can be allowed to air dry; a gentle heat lamp application speeds epithelization. In an area where external contamination is likely, a closed dressing is preferable. The more superficial a STSG is cut, the faster the donor site will heal. The healing of the STSGs donor sites take place over seven to fourteen days (Fig. 8 a,b). Donor sites from which thicker split grafts are cut may not heal for several weeks

Alternatively, donor site are dressed with artificial semi-permeable transparent dressings (e.g. Biobrane ${ }^{\circledR}$, Opsite $^{\circledR}$ or Tegaderm ${ }^{\circledR}$ ) or biologic dressings (e.g. cadaveric skin, sterile irradiated allograft, pig skin, amniotic membrane, cultured keratinocyte grafts) (Fedman, 1991; Voineskos, 2009). Thin STSGs usually leave minimal scarring, whereas the thicker STSGs tend to produce hypertrophic scarring in some patients.
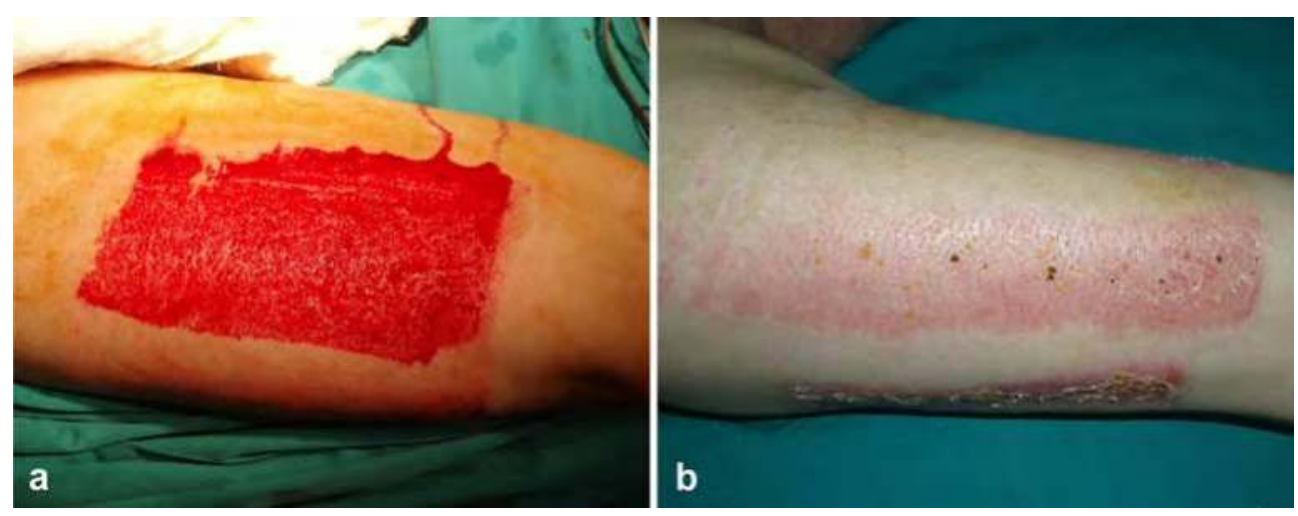

Fig. 8. (a) View of a STSG donor site on the right anterolateral thigh. (b) View of the same donor site on the fourteenth day.

\subsection{Complications of split-thickness skin grafts}

Graft contraction, graft failure, hyperpigmentation, itchiness and dryness of the graft, durability and growth problems are the most common complications of split- thickness skin grafting.

Primary contraction, an elastic recoil of the skin caused by retractile forces, occurs as soon as the graft is harvested. The contraction of a healing graft and wound is referred to as secondary contraction. Secondary contraction, a longer process and clinically more important, is probably caused by a combination of skin graft and host bed contraction. The dermal component of grafted skin appears to exert the main influence on secondary contraction. The thinner the skin graft, the less the primary graft contracture and the more marked the 
secondary graft contracture. Primary graft contracture is approximately $40 \%$ of graft surface for a FTSG, 20\% for a medium thickness STSG, and 10\% for a thin STSG (Senchenkov et al., 2009). The contraction of a wound covered by a STSG can be inhibited by splinting, which needs to be continued for four to six months to overcome the acute effect of the myofibroblasts.

The causes of split thickness skin graft failure are listed in Table 2. Most skin graft failures can be ascribed to flaws in the recipient bed. Tissue with limited blood supply, such as bone, cartilage or tendon or sites with necrosis or infection do not accept skin graft (Fig. 2a, Fig. 3a, Fig. 4). Chronic wounds must be free of pus and should have a healthy, pink to beefy-red appearance with an ideal wound $\mathrm{pH}$ of 7.4 or higher. All granulation tissues contain bacteria, but not all are infected. Particular attention should be paid to eliminating Streptococcus. Wherever possible, underlying systemic health problems causing the wound, such as venous stasis and arterial occlusion, should be corrected before skin grafting is attempted.

Causes of Split-Thickness Skin Graft Failure

- Inadequate recipient bed (poor vascularity)

- Hematoma, seroma

- Inadequate graft fixation and graft shearing

- Infection (in particular Streptococcus, which can "eat up" a graft within 24 hours)

- Technical errors (too thick or too thin graft, upside-down graft.

- $\quad$ Systemic health problems and bad nutritional status

Table 2. Causes of Split-Thickness Skin Graft Failure

Hyperpigmentation of the skin graft is variable and depends on the amount of pigmentation present in the donor site. Generally, STSGs darken more than FTSGs. Although FTSGs maintain the best pigment match, STSGs often develop significantly dark pigmentation. Sunshine should be avoided for the first six months by use of sun-blocking agents or clothing to prevent long-lasting hyperpigmentation developing in a new skin graft. Both STSGs and their donor sites may scale and remain itchy and dry for many months because the lubricating sebaceous glands have been temporarily devitalized. Lubrication with greasy ointment such as Vaseline, lanolin or cocoa butter helps to replace the lubricating function. Thick STSGs have greater resistance to trauma. Although FTSGs grow successfully in children, the growth of STSGs may be limited.

\section{Preservation of split-thickness skin grafts}

In order to close skin defects, skin grafts are best stored on its donor site and harvested painless within five days (Shepard, 1972). Skin grafts may also be stored for longer periods, away from the patient, by being refrigerated. Such grafts may be moistened in sterile saline and then placed in a refrigerator at $4{ }^{\circ} \mathrm{C}$ in a sterile Petri dish labeled with the patient's name and the date of graft harvesting. It may be wise to discard grafts after 8 days, although grafts may be kept for 2 or 3 weeks (Senchenkov et al., 2009). 
Long-term storage of autografts and allograft requires special techniques to protect against cell death. Freezing causes tissue death because of concentration within the cell, leaving behind a lethal concentration of salts. Protective agents such as $15 \%$ glycerol or $10 \%$ dimethyl sulfoxide (DMSO) in Ringer's solution and storage at $-70{ }^{\circ} \mathrm{C}$ with liquid nitrogen help to protect against this type of injury and allow viable skin to be preserved for up to 28 days (Lawrence, 1972). Control of the rate of freezing reduces the damage caused by intracellular ice crystals. The best results were obtained when grafts were slowly frozen and rapidly thawed.

The other technique of storage is freeze-drying of skin for storage at room temperature. Freeze drying maintains most of the structural details of cells and presumably leaves many of the proteins and enzymes of the tissue intact. The process involves rapid freezing of the tissue by immersing it in liquid nitrogen or chilled isopentane. High-speed freezing reduces the mechanical distortion of the microscopic structure caused by the slow growth of ice crystals in and between the cells. This tissue is subsequently kept frozen while water is removed from the solid state by sublimation. The dried tissue is usually sealed in a vacuum and stored at room temperature (Yukna et al., 1977)

Specialized skin banks have been developed to store large amounts of cadaver skin for treatment of massive burns (Konstantinow, 1991). Standardized techniques for cadaver skin graft preservation use glycerol and rapid freezing with liquid nitrogen (Ninneman et al., 1978). The treated allografts are thawed and used for temporary burn dressings, to be changed every five days. Pigskin xenografts have also been used fresh or frozen for burn treatment.

\section{Conclusion}

STSGs constitute the most commonly performed procedures for the closure of skin defects that can not be closed with the simple approximation of the wound edges. When a patient has a full-thickness loss-of-skin defect exceeding 30\% of the body area, STSGs taken from the patient are not available in sufficient quantity. Cultured autologous keratinocytes may be used to close larger open wounds in such situations. Unfortunately, the lack of dermis makes the epidermal graft rather thin and fragile. Intensive efforts to develop epidermal and dermal skin substitutes show the greatest potential, at present, for future success.

\section{References}

Argenta, L.C., \& Morykwas, M.J. (1997). Vacuum-assisted closure: a new method for wound control and treatment: clinical experience. Ann Plast Surg, Vol. 38, No.6, pp.563-576, ISSN: 0148-7043

Bernstein, B.H., \& Tam, H. (2005). Combination of subatmospheric pressure dressing and gravity feed antibiotic instillation in the treatment of post-surgical diabetic foot wound: a case rseries. Wounds, Vol.17, No.2, pp.37-48.

Blair, V.P., \& Brown, J.B. (1929). The use and uses of large split skin grafts of intermediate thickness. Surg Gynecol Obstet, Vol.49, pp.82-97. 
Fedman, D.L. (1991). Which dressing for split-thickness skin graft donor sites? Ann Plast Surg, Vol.27, No.3, pp.288-91, ISSN: 0148-7043

Fowler, A., \& Dempsey, A. (1998). Split-thickness skin graft donor sites. J Wound Care, Vol.7, No.8, pp.399-402.

Gaboriau, H.P. \& Murakami, C.S. (2001). Skin anatomy and flap physiology. Otolaryngol Clin North Am, Vol.34, No.3, pp.555-69, ISSN: 0030-6665

Gonzalez-Ulloa, M.; Castillo, A., Stevens, E., Alvarez, Fuertes, G., Leonelli, F. \& Ubaldo F. (1954). Preliminary study of the total restoration of the facial skin. Plast Reconstr Surg, Vol.13, No.3, pp.151-161, ISSN: 0032-1052

Konstantinow, A., Mühlbauer, W., Hartinger, A., \& von Donnersmarck, G.G. (1991). Skin banking: a simple method for cryopreservation of split-thickness skin and cultured human epidermal keratynocytes. Ann Plast Surg, Vol.26, No.1, pp. 89-97, ISSN: 0148-7043

Kusuma, S., Vuthori, R.K., Piliang, M., \& Zins, J.E. (2010). Skin Anatomy and Physiology. In: Plastic and Reconstructive Surgery, Siemionow, M.Z., Eisenmann-Klein, M. (Eds) pp.161-171., Springer-Verlag, ISBN 978-1-84882-512-3, USA.

Lawrence, J.C. (1972). Storage and skin metabolism. Br J Plast Surg, Vol.25, No.4, pp.440-453, ISSN: 0007-1226

Ninneman, J.L., Fisher, J.C., \& Frank, H.A. (1978). Clinical skin banking: a simplified system for processing, storage, and retrieval of human allografts. J Trauma, Vol.18, No.10, pp. 723-725, ISSN: 0022-5282

Scherer, L.A., Shiver, S., \& Chang M. (2002). The vacuum assisted closure device: a method of securing skin grafts and improving graft survival. Arch Surg, Vol.137, No.8, pp.930-933, ISSN: 0004-0010

Schneider, A.M., Morykwas, M.J., \& Argenta, L.C. (1998). A new and reliable method of securing skin grafts to the difficult recipient bed. Plast Reconstr Surg, Vol.102, No.4, pp.1195-1198, ISSN: 0032-1052

Senchenkov, A., Valerio, I.L., \& Manders, E.K. (2009). Grafts. In: Plastic Surgery: Indications and Practice, Guyuron, B., Eriksson, E., Persing, J.A. (Eds.)pp. 95-104, Elsevier, ISBN 13: 978-1-4160-4081-1, USA.

Shepard, G.H. (1972). The storage of split-skin grafts on their donor sites. Clinical and experimental study. Plast Reconstr Surg, Vol.49, No.2, pp.115-122, ISSN: 00321052

Stal, S., Spira, M., \& Hamilton, S. (1987). Skin morphology and function. Clin Plast Surg, Vol.14, No.2, pp.201-208, ISSN: 0094-1298.

Tanner, J.C., Vandeput, J., \& Olley, J.F. (1964). The mesh skin graft. Plast Reconstr Surg, Vol.34, (Sep 1964), pp.287, ISSN: 0032-1052

Teot, L., (2004). The theory of negative pressure wound therapy (NPWT). Wounds, Vol.16, No.2, (Suppl), pp. 2-5,

Vitness, LM. (1977) Grafting of Skin. Surg Clin North Am, Vol.57, No.5, pp. 939-960, ISSN: 0039-6109

Voineskos, S.H., Ayeni, O.A., McKnight, L., Thoma, A. (2009). Systematic review of skin graft donor-site dressings. Plast Reconstr Surg, Vol.124, No.1, pp.298-306, ISSN: 0032-1052 
Yukna, R.A., Tow, H.D., Carrol, P.B., Vernino, A.R., \& Bright, R.W. (1977). Evaluation of the use of freze-dried skin allografts in the treatment of human mucogingival problems. J Periodontol, Vol.48, No.4, pp.187-193, ISSN: 0022-3492 


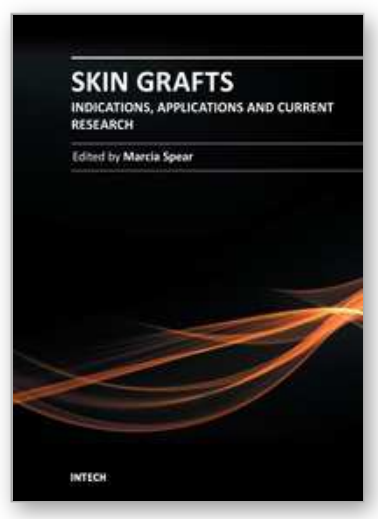

\author{
Skin Grafts - Indications, Applications and Current Research \\ Edited by Dr. Marcia Spear
}

ISBN 978-953-307-509-9

Hard cover, 368 pages

Publisher InTech

Published online 29, August, 2011

Published in print edition August, 2011

The procedure of skin grafting has been performed since 3000BC and with the aid of modern technology has evolved through the years. While the development of new techniques and devices has significantly improved the functional as well as the aesthetic results from skin grafting, the fundamentals of skin grafting have remained the same, a healthy vascular granulating wound bed free of infection. Adherence to the recipient bed is the most important factor in skin graft survival and research continues introducing new techniques that promote this process. Biological and synthetic skin substitutes have also provided better treatment options as well as HLA tissue typing and the use of growth factors. Even today, skin grafts remain the most common and least invasive procedure for the closure of soft tissue defects but the quest for perfection continues.

\title{
How to reference
}

In order to correctly reference this scholarly work, feel free to copy and paste the following:

Tamer Seyhan (2011). Split-Thickness Skin Grafts, Skin Grafts - Indications, Applications and Current Research, Dr. Marcia Spear (Ed.), ISBN: 978-953-307-509-9, InTech, Available from:

http://www.intechopen.com/books/skin-grafts-indications-applications-and-current-research/split-thicknessskin-grafts

\section{INTECH}

open science | open minds

\section{InTech Europe}

University Campus STeP Ri

Slavka Krautzeka 83/A

51000 Rijeka, Croatia

Phone: +385 (51) 770447

Fax: +385 (51) 686166

www.intechopen.com

\section{InTech China}

Unit 405, Office Block, Hotel Equatorial Shanghai

No.65, Yan An Road (West), Shanghai, 200040, China 中国上海市延安西路65号上海国际贵都大饭店办公楼 405 单元

Phone: +86-21-62489820

Fax: +86-21-62489821 
(C) 2011 The Author(s). Licensee IntechOpen. This chapter is distributed under the terms of the Creative Commons Attribution-NonCommercialShareAlike-3.0 License, which permits use, distribution and reproduction for non-commercial purposes, provided the original is properly cited and derivative works building on this content are distributed under the same license. 